\title{
Social network and activities in relation to mortality from cardiovascular diseases, cancer and other causes: a 12 year follow up of the Study of Men Born in 1913 and 1923
}

\author{
Lennart Welin, Bo Larsson, Kurt Svärdsudd, Bodil Tibblin, Gösta Tibblin
}

\begin{abstract}
Objective-The aim was to examine the relationship between social network and activities and causes of death.
\end{abstract}

Design-The study was a prospective cohort study of middle aged men examined in 1973 and followed for 12 years.

Setting-Gothenburg, Sweden.

Subjects-The subjects were 76960 year old and 22050 year old men who had participated in a health examination.

Measurements and main results-Main outcome measures were mortality from cardiovascular diseases, cancer and other causes. In multivariate analyses cardiovascular mortality was related to baseline blood pressure $(p<0.001)$, smoking habits $(p=0.002)$, myocardial infarction or stroke $(p<0.001)$, and a low level of social activities $(p=0.04)$. Cancer mortality was related to age $(p=0.003)$ and smoking habits $(p=0.001)$. Other causes of death were related to poor perceived health $(p=0.02)$ and a low level of home activities $(p=0.004)$. In univariate analyses the above risk factors were strongly related to all three causes of death. In addition cardiovascular mortality was related to age, a low level of home and outside home activities, few persons in the household, and poor perceived health. Cancer mortality was related to poor perceived health, few persons in the household, and a low level of social activities. Other causes of death were related to living alone, poor perceived health, and a low level of social and outside home activities.

Conclusions - Well known risk factors for premature mortality like smoking, hypertension, and major cardiovascular disease are verified. Middle aged men with a good "social network" (here measured as a high level of social, home, and outside home activities) may be partly protected against non-cancer mortality.

The social environment, measured as social support, social network, or social activities, has attracted a considerable amount of interest during the past decade because of its possible role as a protector against various diseases and premature mortality. ${ }^{2}$ Most of these studies have been case-controlled studies with their inherent difficulties in disentangling whether poor social support contributes to disease causation or whether disease leads to poor social support and network (for review, see ${ }^{1}$ ). There are, however, several prospective studies in which poor social network has been linked to an increased mortality during follow up. ${ }^{3-11}$ These findings may indicate that a poor social network is one factor of importance in disease causation in humans.

A poor social network seems to influence morbidity and mortality in a general way and is probably not linked to any specific disease outcome. ${ }^{1}$ In the Honolulu Heart Study ${ }^{12}$ no association was found between social network scales and the incidence of coronary heart disease. In the Alameda County Study the "social network index" was associated with mortality from different causes of death including cancer, coronary heart disease, and other cardiovascular diseases, ${ }^{13}$ again indicating a non-specific effect on mortality.

We have previously shown that the level of social and other activities is inversely related to mortality during nine years of follow up among middle aged men. ${ }^{9}$ Follow up has now been extended to 12 years and in this report the relations of various social network measurements to mortality from cancer, cardiovascular diseases and other causes of death are presented.

\section{Methods}

STUDY POPULATION

In 1963 a random sample of 50 year old men (all born in 1913) was drawn from the population register in Gothenburg $(n=973)$ and invited to a health examination. Eight hundred and fifty five men $\left(88^{\circ}{ }_{0}\right.$ of those invited) participated. Ten years later, in 1973, a new sample of men born in 1913 (60 year olds) was drawn including all men from the 1963 sample who were still alive and living in Gothenburg and men who had moved into the area since 1963. This sample consisted of 945 men out of whom $787\left(83^{\circ}{ }_{0}\right)$ participated in a morning examination and $769\left(81^{\circ}{ }_{0}\right)$ in an afternoon examination one week later. In addition, we invited another random sample of men born in 1923 ( 50 year olds). Out of the 292 men invited, $226\left(77^{\circ}{ }_{0}\right)$ participated in the morning examination and $220\left(75^{\circ}{ }_{0}\right)$ in the afternoon examination.

Men participating in the afternoon examination in 1973-74 $(n=989)$ form the study population of this report. All these men also participated in the morning examination.

\section{EXAMINATIONS}

The participants came to the morning examination after fasting overnight. Blood was drawn for serum cholesterol determinations and blood pressure measured in the right arm after five minutes' rest in the seated position. 
Questionnaires about smoking habits, alcohol consumption, and previous stroke or myocardial infarction were completed. Smoking habits were coded as $1=$ never smoked, $2=$ ex-smokers, $3=$ smoking $1-4 \mathrm{~g} /$ day, $4=$ smoking $5-14 \mathrm{~g} /$ day, $5=$ smoking $15-24 \mathrm{~g} /$ day, and $6=$ smoking 25 $\mathrm{g} /$ day or more ( 1 cigarette $=1 \mathrm{~g}$ tobacco, 1 cigarillo $=2 \mathrm{~g}$, and 1 cigar $=5 \mathrm{~g}$ ). Pipe smokers' consumption was calculated from number of $50 \mathrm{~g}$ tobacco packs/week. Alcohol consumption was calculated from the reported frequency of drinking and the quantity and type of alcohol consumed. ${ }^{14}$ Reported cases of myocardial infarction or stroke were verified from hospital and outpatient clinic records.

The afternoon examination included a detailed questionnaire about various activities which was completed with the help of a psychologist. The participants were asked about their marital status and number of persons in their household. Questions about activities during the past year (table I) were divided into home activities (10 items), outside home activities (14 items), and social activities ( 8 items). There were three possible responses; no (score $=0$ ), occasionally $($ score $=1)$, and often/regularly $($ score $=2)$. The ratings for each question were totalled to give a theoretical range for home activities of $0-20$ points, for outside home activities of $0-28$ points, and for social activities of $0-16$ points. The participants were also asked to grade their health on a seven grade scale ranging from excellent $($ score $=1)$ to very poor $($ score $=7)$.

FOLLOW UP AND CLASSIFICATION OF CAUSES OF DEATH

All participants have been followed up until the end of 1985 with respect of mortality with the help of newspaper obituaries, parish registers, hospital records, Statistics Sweden (the Central Bureau of Statistics), and a re-examination in 1980. Follow up with respect to mortality was $100^{\circ}{ }_{0}$. Causes of death were coded according to the International classification of diseases (8th revision 1965). For the purpose of this report the causes of death were classified in three groups; cancer (ICD code 140-239), cardiovascular diseases (ICD code 390458 ), and all other causes of death.

\section{STATISTICAL METHODS}

Statistical tests were done by comparing each of the three groups of causes of death with the survivor group (excluding the two other groups from the analyses). Student's $t$ test and the $\chi^{2}$ test were used to analyse differences in mean values and proportions. The correlation coefficients presented are Pearson or Spearman correlation coefficients. For multivariate analyses, the logistic regression technique was used. All statistical tests were two tailed. Analyses were done with the Statistical Analysis System (SAS) software. ${ }^{15}$

\section{Results}

During the 12 year follow up period until 1985 there were 215 deaths $\left(22^{\circ}{ }_{0}\right), 63$ from cancer, 122 from cardiovascular diseases, and 30 from other causes. There were 190 deaths $\left(25^{\circ}{ }_{0}\right)$ among the 60 year old men and 25 deaths $\left(11^{\circ}{ }_{0}\right)$ among the 50 year old men.

\section{UNIVARIATE ANALYSES}

Among the three traditional risk factors for coronary heart disease, systolic blood pressure was higher and smoking was more prevalent

Table I Home activities, outside home activities and social activities. Possible responses; never or no (score $=0$ ), occasionally (score $=1$ ), and often/regularly (score $=2$ )

\begin{tabular}{lll}
\hline Home activities & Outside home activities & Social activities \\
\hline Repairs & Swimming, bathing & Parties at home \\
Hobbies (eg stamps, photography) & Cycling, skiing, skating & Organised sports (soccer, handball, etc) \\
Studying & Hunting or fishing & Dancing \\
Reading & Mushroom or berry picking & Visiting relatives \\
Gardening & Cinema & Visiting friends \\
Painting, carpentry & Theatre & Trade union meetings \\
Boat & Concerts & Other association meetings \\
Car & Sport events & Study circles \\
Sauna bathing & Horse racing events & \\
Exercise bicycle (indoor) & Restaurant dining & \\
& Museums, exhibitions & \\
& Travelling abroad & \\
& Travelling in Sweden & \\
& Church attendance & \\
\end{tabular}

Table II Traditional coronary heart disease risk factors, social network, activities, and health in relation to various causes of mortality during 12 years of follow up

\begin{tabular}{|c|c|c|c|c|c|c|c|c|}
\hline Variable & $\begin{array}{l}\text { Cancer deaths } \\
n=63 \\
\text { Mean }\end{array}$ & $(S D)$ & $\begin{array}{l}\text { Cardiovascular } \\
\text { deaths, } n=122 \\
\text { Mean }\end{array}$ & $(S D)$ & $\begin{array}{l}\text { Other causes } \\
\text { of death, } n=30 \\
\text { Mean }\end{array}$ & $(S D)$ & $\begin{array}{l}\text { Survivors } \\
n=774 \\
\text { Mean }\end{array}$ & $(S D)$ \\
\hline $\begin{array}{l}\text { Systolic blood pressure }(\mathrm{mm} \mathrm{Hg}) \\
\text { Smoking, points } \\
\text { Serum cholestrol (mg\%) } \\
\qquad(\mathrm{mmol} / \text { litre })\end{array}$ & $\begin{array}{l}148 \cdot 4 \\
3 \cdot 51 \neq \\
251 \\
6 \cdot 49\end{array}$ & $\begin{array}{l}(25 \cdot 1) \\
(1 \cdot 42) \\
(47) \\
(1 \cdot 22)\end{array}$ & $\begin{array}{l}155 \cdot 2 \S \\
3 \cdot 11^{\star} \\
256 \\
6 \cdot 62\end{array}$ & $\begin{array}{l}(29 \cdot 0) \\
(1 \cdot 59) \\
(48) \\
(1 \cdot 24)\end{array}$ & $\begin{array}{l}139 \cdot 3 \\
3 \cdot 03 \\
244 \\
6 \cdot 31\end{array}$ & $\begin{array}{l}(25 \cdot 2) \\
(1.63) \\
(53) \\
(1 \cdot 27)\end{array}$ & $\begin{array}{l}142 \cdot 9 \\
2 \cdot 78 \\
249 \\
6 \cdot 40\end{array}$ & $\begin{array}{l}(22 \cdot 8) \\
(1 \cdot 49) \\
(46) \\
(1 \cdot 19)\end{array}$ \\
\hline $\begin{array}{l}\text { Unmarried (\%) } \\
\text { Number of persons per household } \\
\text { Home activities (points) } \\
\text { Outside home activities (points) } \\
\text { Social activities (points) }\end{array}$ & $\begin{array}{l}23 \cdot 8 \\
2 \cdot 05 \dagger \\
6.92 \\
7 \cdot 26 \\
4 \cdot 55 t\end{array}$ & $\begin{array}{l}(0 \cdot 63) \\
(3 \cdot 92) \\
(3 \cdot 62) \\
(2 \cdot 22)\end{array}$ & $\begin{array}{l}23 \cdot 8 \\
2 \cdot 14 \dagger \\
5 \cdot 80 \ddagger \\
6 \cdot 97 \dagger \\
4 \cdot 45 \S\end{array}$ & $\begin{array}{l}(0 \cdot 76) \\
(3 \cdot 42) \\
(3 \cdot 58) \\
(2 \cdot 36)\end{array}$ & $\begin{array}{l}43 \cdot 3 \ddagger \\
1 \cdot 77 \S \\
4 \cdot 33 \S \\
5 \cdot 77 \ddagger \\
4 \cdot 33^{\star}\end{array}$ & $\begin{array}{l}(0 \cdot 77) \\
(2 \cdot 76) \\
(3 \cdot 55) \\
(2 \cdot 32)\end{array}$ & $\begin{array}{l}17 \cdot 8 \\
2 \cdot 37 \\
7 \cdot 09 \\
7 \cdot 99 \\
5 \cdot 33\end{array}$ & $\begin{array}{l}(0 \cdot 89) \\
(3 \cdot 52) \\
(3 \cdot 57) \\
(2 \cdot 23)\end{array}$ \\
\hline \multirow{2}{*}{$\begin{array}{l}\text { Perceived health } \\
\text { MI or stroke before examination in } \\
1973-74(\%)\end{array}$} & $2 \cdot 87^{\star}$ & $(1.61)$ & $3.03 \S$ & $(1 \cdot 76)$ & $3.41 \ddagger$ & $(1 \cdot 82)$ & $2 \cdot 39$ & $(1.43)$ \\
\hline & $4 \cdot 8$ & & $21 \cdot 3 \S$ & & $3 \cdot 3$ & & $2 \cdot 6$ & \\
\hline
\end{tabular}


among those who later died from cardiovascular disease than among survivors (table II). Smoking was also more prevalent among those who later died from cancer. Men who died from other causes did not differ from survivors with respect to coronary heart disease risk factors (table II).

Marital status did not differ between survivors and those who later died from cancer and cardiovascular diseases. Among men who died from other causes, $43^{\circ}{ }_{0}$ were unmarried (divorced, widowers or bachelors), a significant difference compared to $18^{\circ}$ o among survivors (table II). Men who died (irrespective of cause) lived in households with fewer persons than men who survived (table II). Men who died from cardiovascular diseases and from other causes had significantly lower scores (points) for all three types of activities compared with survivors, while men who died from cancer had significantly lower scores for social activities only (table II).

Men who died had perceived themselves as having poorer health (scores were higher) than men who survived (table II). Previous myocardial infarction or stroke before the baseline examination was more common $(21.3 \%)$ among those who died from cardiovascular diseases than among survivors $(2.6 \%$, table II). Conversely the 50 men with myocardial infarction or stroke before the examination had a higher cardiovascular disease mortality $(52 \%)$ during follow up than the other 939 men $\left(10^{\circ}, \mathrm{p}<0.001\right)$.

Figures 1-3 further illustrate the graded relationship between the factors that were statistically the most strongly related to the three causes of death. Cancer mortality (fig 1A) was lowest among non-smokers $(1.5 \%$ ) and was successively higher among ex-smokers and moderate smokers. Heavy smokers had the highest mortality $\left(10 \cdot 4^{\circ}{ }_{0}\right)$. Those living in households consisting of 1-2 persons had higher cancer mortality than those living in larger households (fig 1B). Participants with low scores for social activities (fig 1C, $0-3$, lowest quartile) had the highest cancer mortality $\left(10 \cdot 6^{\circ}{ }_{0}\right)$, while participants with scores above 3 (the three highest quartiles) had approximately the same cancer mortality $\left(4 \cdot 9-5 \cdot 7^{\circ}{ }_{0}\right)$.

Cardiovascular mortality (fig 2A) was lowest among men with systolic blood pressure of 140 or less, $8 \cdot 7-6 \cdot 9 \%$ (the two lowest quartiles), and increased successively to $18.9^{\circ}{ }_{0}$ among men with a blood pressure of 160 or more (the highest quartile). For social activities (fig 2B) there was a gradual increase in cardiovascular disease mortality with decreasing activity from $8.2^{\circ}{ }_{0}$ to $18 \cdot 6^{\circ}$. Participants grading their health as good (fig 2C, scores 1-2) had the lowest cardiovascular disease mortality, $9 \cdot 8^{\circ}{ }_{0}-7 \cdot 8^{\circ}{ }_{0}$. With lower grading of health there was an increasing cardiovascular disease mortality to $15 \cdot 1{ }^{\circ}$ o (grade 3) and $17 \cdot 7^{\circ}$ (grade 4 or more).

Figure 3 illustrates the three variables with the strongest correlation to other causes of death. For home activities (fig 3A) there is a successively increasing mortality from 0.5 to $5.7^{\circ}$ o with successively lower levels of activity. Number of persons per household shows a similar relation, those with four or more persons per household (fig 3B) having a mortality of $1 \cdot 1^{\circ}{ }_{0}$ which increased successively to $9 \cdot 3^{\circ}{ }_{0}$ among those living alone. Mortality among those who graded their health as good (fig 3C, scores $1-2$ ) was $1 \cdot 6^{\circ}{ }_{0}$. For grades 3 and 4 or more, mortality was $4 \cdot 3^{\circ}{ }_{0}$ and $5 \cdot 2 \%$ respectively.

The 60 year old men had significantly higher blood pressure and smoked less than the 50 year old men. Their marital status did not differ from 50 year old men but the 60 year olds lived in smaller households (data not shown); 60 year old men also had significantly lower points for all three activity variables than 50 year old men. Mean values for home activities were 6.57 and $7 \cdot 79$ respectively; for outside home activities $7 \cdot 46$ and 8.77 respectively; and for social activities 4.95 and 5.80 respectively (all significant at $p<0.001$ ).

Neither frequency of drinking nor type or amount of alcohol consumed was related to any of the three groups of causes of death. Total alcohol
Figure 1 Cancer mortality during 12 years of follow up in relation to smoking habits $(A)$, the number of persons in the household $(B)$, and social activities $(\boldsymbol{C})$. Univariate analyses.

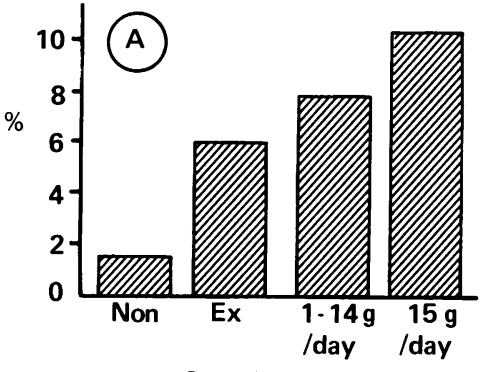

Smoking habits

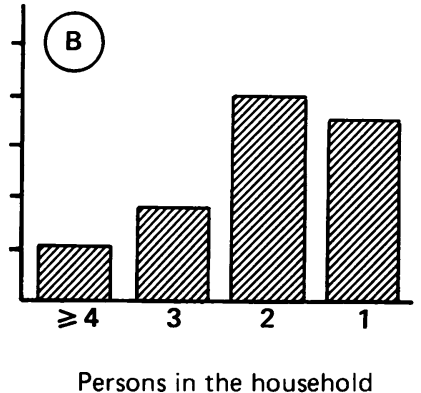

Persons in the household

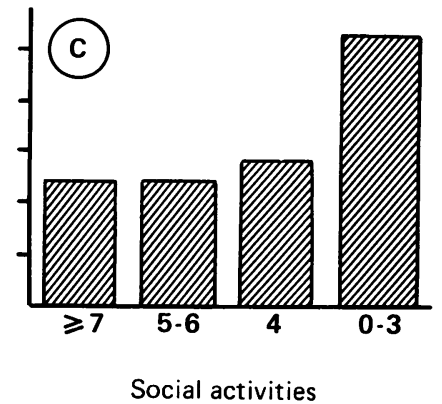

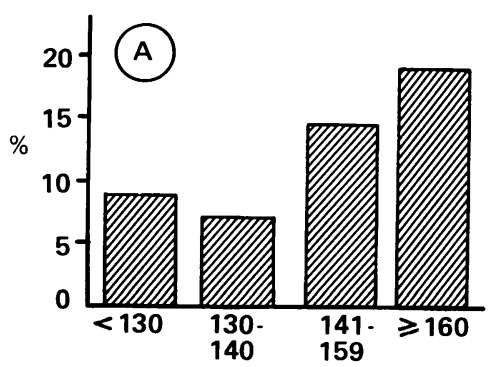

Systolic blood pressure $(\mathrm{mm} \mathrm{Hg})$

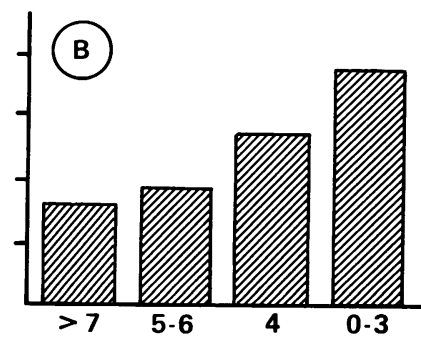

Social activities

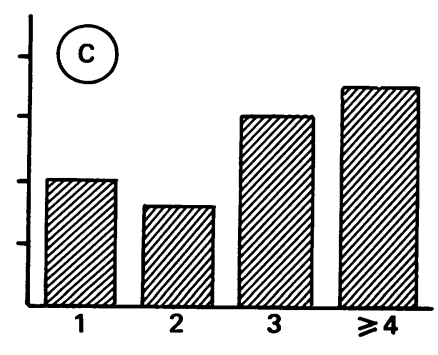

Perceived health
Figure 2 Cardiovascular mortality during 12 years quartiles of systolic blood Univariate analyses. 
Figure 3 Other causes of death during 12 years of follow up in relation to home activities $(A)$, the number of persons in the household $(B)$, and perceived health $(C)$. Univariate analyses.
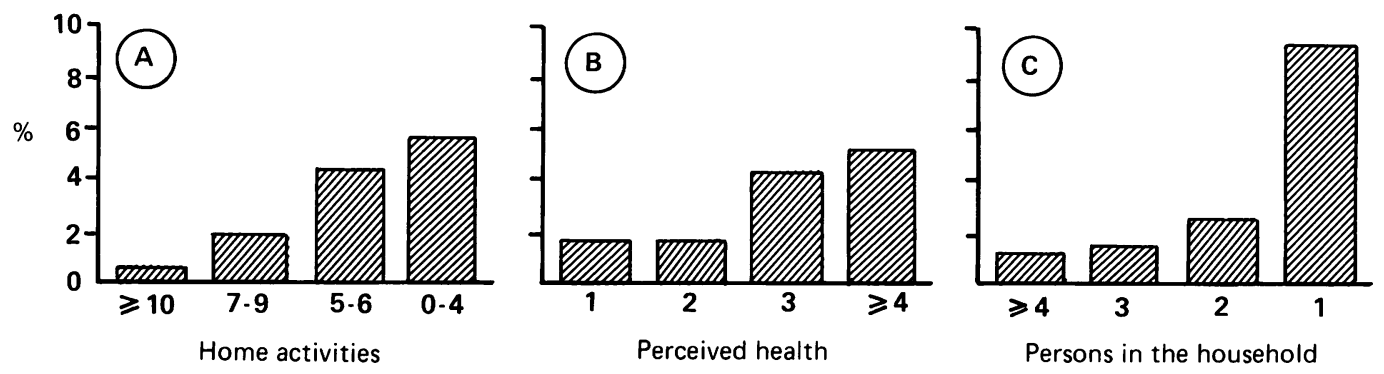

consumption, expressed as gram alcohol per person per year, was not related to any of the three groups of causes of death (data not shown).

\section{INTERCORRELATIONS}

There was a highly significant correlation $(\mathrm{r}=0.44-0.53)$ between all three activity variables (table III) and between the two social network variables marital status and number of persons per household. There were significant correlations also between these two variables and the activity variables (except between marital status and outside home activities). Smoking did not correlate with any variable except for a negative correlation with blood pressure. Blood pressure was negatively correlated with the number of persons in the household and social activities.

The possible confounding factors (see below) of perceived health and myocardial infarction or stroke before the examination were correlated with each other (table III). Poor perceived health was more common among unmarried men and among those living in small households or alone. Poor health was also strongly correlated to low scores for all three activities. Men with myocardial infarction or stroke before the examination also had lower scores for all three activities compared with men without myocardial infarction or stroke (table III).

\section{CONFOUNDING VARIABLES}

Age is, of course, an important confounding variable since it is related not only to mortality but also to almost all social network and activity variables (the level of activity decreases with age, see above). A poor social network and low levels of activities appear to be important predictors of various causes of mortality, but those already ill at the baseline examination (higher scores for perceived health or previous myocardial infarction or stroke) might be more isolated and less active due to the illness (table III) and the illness makes them more prone to death. This is evident from table II; men who died during follow up perceived themselves as having a poorer health than those who survived. Perceived health was poorest among those dying from cardiovascular diseases and other causes. Participants with confirmed (and not only self reported) diseases like myocardial infarction and stroke at the baseline examination also had a high cardiovascular disease mortality during follow up. Therefore, health status at the baseline examination is an important confounder and must be taken into account when the predictive importance of the social network and activities is analysed.

\section{MULTIVARIATE ANALYSES}

The logistic regression technique was used and only variables significantly related to the specific group of causes of deaths in the univariate analyses were entered into the equation. Since the three activity variables were strongly correlated with each other (table III) only the variable with the statistically strongest relation to the end point was chosen. Futhermore, each group of causes of death was analysed compared to survivors excluding the two other groups of causes of death from the analysis.

For cancer mortality none of the social network and activity variables remained as significant predictors (table IV). Age and smoking habits, however, were still related to an increased risk of cancer death.

For deaths from cardiovascular diseases, social activities remained as a weak but significant predictor (table IV). Stronger predictors of cardiovascular disease mortality were systolic blood pressure and smoking habits, as well as myocardial infarction or stroke before the baseline examination.

For other causes of death a low home activity score as well as poor perceived health remained as significant predictors (table IV).

\section{Discussion}

This prospective study confirms the well known relation between mortality from cancer and

Table III Correlations (expressed as correlation coefficients, $r$ ) between factors significantly related to any of the three groups of causes of death

\begin{tabular}{|c|c|c|c|c|c|c|c|c|}
\hline & $\begin{array}{l}\text { Systolic } \\
\text { blood } \\
\text { pressure }\end{array}$ & Smoking & $\begin{array}{l}\text { Perceived } \\
\text { health }\end{array}$ & $\begin{array}{l}\text { MI or } \\
\text { stroke }\end{array}$ & Married & $\begin{array}{l}\text { Persons } \\
\text { per household }\end{array}$ & $\begin{array}{l}\text { Home } \\
\text { activities }\end{array}$ & $\begin{array}{l}\text { Outside } \\
\text { home } \\
\text { activities }\end{array}$ \\
\hline $\begin{array}{l}\text { Systolic blood pressure } \\
\text { Smoking } \\
\text { Perceived health } \\
\text { MI or stroke before baseline } \\
\text { examination } \\
\text { Married }^{\mathrm{a}} \\
\text { Person per household } \\
\text { Home activities } \\
\text { Outside home activities } \\
\text { Social activities }\end{array}$ & $\begin{array}{r}-\overline{0} \cdot 15 \\
0.01 \\
-0.01 \\
-0.02 \\
-0.14 \\
-0.06 \\
0.01 \\
-0.07\end{array}$ & $\begin{array}{r}0.02 \\
-0.03 \\
-0.04 \\
-0.05 \\
-0.04 \\
-0.05\end{array}$ & $\begin{array}{r}0.20 \\
-0.14 \\
-0.10 \\
-0.22 \\
-0.18 \\
-0.20\end{array}$ & $\begin{array}{r}-\overline{0.04} \\
-0.05 \\
-0.11 \\
-0.11 \\
-0.07\end{array}$ & $\begin{array}{r}-\overline{0} \\
-0.96 \\
0.27 \\
0.06 \\
0.16\end{array}$ & $\begin{array}{l}- \\
0 \cdot 22 \\
0 \cdot 09 \\
0 \cdot 12\end{array}$ & $\begin{array}{l}- \\
0.46 \\
0.44\end{array}$ & 0.53 \\
\hline
\end{tabular}

MI = myocardial infarction 
Table IV Multiple logistic regression analysis of risk factors (significant in univariate analysis) for cancer deaths, cardiovascular deaths, and other causes of deaths. Each group of causes of deaths was compared to the group of survivors

\begin{tabular}{|c|c|c|c|c|c|c|c|c|c|}
\hline \multirow[b]{2}{*}{ Variable } & \multicolumn{3}{|c|}{ Cancer deaths } & \multicolumn{3}{|c|}{ Cardiovascular deaths } & \multicolumn{2}{|c|}{ Other causes of death } & \multirow[b]{2}{*}{ p Value } \\
\hline & $\begin{array}{l}\text { Regression } \\
\text { coefficients }\end{array}$ & $S E M$ & p Value & $\begin{array}{l}\text { Regression } \\
\text { coefficient }\end{array}$ & $S E M$ & p Value & $\begin{array}{l}\text { Regression } \\
\text { coefficient }\end{array}$ & $S E M$ & \\
\hline Age & 0.221 & 0.073 & 0.003 & 0.053 & 0.033 & $0 \cdot 11$ & 0.036 & 0.048 & 0.45 \\
\hline Systolic blood pressure & - & - & - & 0.025 & 0.004 & 0.0000 & - & - & - \\
\hline Smoking & $0 \cdot 297$ & 0.092 & 0.001 & $0 \cdot 237$ & 0.076 & 0.002 & - & - & - \\
\hline Perceived health & $0 \cdot 140$ & 0.085 & $0 \cdot 10$ & $0 \cdot 134$ & 0.072 & 0.06 & $0 \cdot 271$ & $0 \cdot 112$ & 0.02 \\
\hline $\begin{array}{l}\text { Myocardial infarction or stroke } \\
\text { before examination } 1973-74\end{array}$ & - & - & - & $2 \cdot 415$ & $0 \cdot 361$ & 0.0000 & - & - & - \\
\hline Unmarried & - & - & - & - & - & - & 0.022 & $0 \cdot 580$ & 0.97 \\
\hline $\begin{array}{l}\text { Number of persons per } \\
\text { household }\end{array}$ & -0.223 & $0 \cdot 200$ & 0.27 & -0.072 & $0 \cdot 148$ & 0.63 & -0.733 & 0.390 & 0.06 \\
\hline Home activities & - & - & - & - & - & - & -0.206 & 0.072 & 0.004 \\
\hline Outside home activities & - & - & - & - & - & - & - & - & - \\
\hline Social activities & -0.096 & 0.069 & $0 \cdot 16$ & -0.113 & 0.054 & 0.04 & - & - & - \\
\hline
\end{tabular}

The three activity variables were strongly related to each other. Therefore only the variable with the statistically strongest association to the endpoint was chosen for the multiple logistic regression

smoking habits. ${ }^{16}$ In univariate analyses, but not in multivariate analysis, number of persons per household and social activities were related to cancer mortality. This is explained by the age factor since a higher age is related to lower levels of both these social network variables and also to a higher incidence of cancer mortality.

Among the traditional risk factors for coronary heart disease, smoking and blood pressure, but not serum cholesterol, were related to cardiovascular mortality both in univariate and multivariate analyses. All social network variables except marital status were also related to cardiovascular mortality in univariate analysis but only social activity remained as an independent predictor after multivariate analysis.

Other causes of death could not be predicted by the traditional coronary heart disease risk factors. The social network variables as well as perceived health were all related to other causes of death in univariate analysis. After multivariate analysis perceived health and home activities remained as independent predictors.

We do not know whether our findings apply to women also. In one study social isolation seemed to be a risk factor for total mortality among women as well as among men $^{3}$ but others ${ }^{45}$ have found that women are less susceptible to a poor social network than men.

Social factors like marital status and level of income also influence the likelihood of participating in a population study. Analysis of the non-participation group at the examination in 1963 showed that these men were more often unmarried, and had more alcohol problems and a lower income than the participants. ${ }^{17}$ The nonparticipants also had significantly higher mortality during follow up. ${ }^{18}$ From these findings one might infer that the impact of a poor social network on mortality is probably greater in the general male population than is evident from the results of this cohort study.

The causal interpretation of the associations between poor social relationships and activities and an increased mortality might be explained by the "drift hypothesis". 19 Those affected by disease drift downward socioeconomically and tend to lose contact with friends and relatives. Our findings partly substantiate this view since we found an association between perceived poor health and a low rating for all activities. Also those men with objectively confirmed disease (myocardial infarction or stroke) had lower ratings for all activities. We do not, however, have any longitudinal data on change in activities in relation to change in health; thus the "drift hypothesis" remains speculative.

The "vulnerability hypothesis" proposed by Casse ${ }^{20}$ might also explain our findings. This hypothesis indicates that social factors or a strong social network (measured by us as an activity score) protects against noxious stimuli which might otherwise cause disease and death. We found that men with high activity scores were less likely to die from cardiovascular diseases and other causes but not from cancer.

Our data may thus support (and do not contradict) the two hypotheses which have been discussed by House and coworkers in a recent review: ${ }^{21}$ (1) lack of social relationships cause disease and death; and (2) sick people are less likely to maintain social relationship and more likely to die because they are sick. Both these mechanisms may be operating at the same time and both increase the mortality risk.

A previous analysis from this study ${ }^{9}$ supported the theory that poor social support and a low grade of social and other activities caused a general susceptibility to disease and death. Our present findings indicate that the risk of dying from cancer is not affected by the social support and the level of activity. Susceptibility to fatal diseases seems to be restricted to cardiovascular diseases and other causes of death. With other measurements of the social environment Jenkins ${ }^{22}$ found that mortality from cancer among males (but not among females) was strongly related to social and demographic factors like living in poverty areas, areas with small households, and high divorce rates.

Two other studies, one Swedish ${ }^{7}$ and one Finnish, ${ }^{10}$ have reported an association between a low index of social network and connections on the one hand and an increased risk of cardiovascular mortality on the other. The social network index of the Swedish study and the social connections index used in the Finnish study were not identical to each other and to our social activity score but include many similarities like contact frequency with friends and relatives and frequency of meetings with associations. This contact frequency with other people might be the most important protective factor of the social network.

We did not measure the quality of home, outside home, and social activities. It may well be that this quality of for example social participation (social activities) is more important than its quantity as a factor of premature mortality. ${ }^{11}$ 
This study was supported by the Swedish Heart-Lung Foundation and the Swedish Medical Research Council (B90-27X-06276-09A).

1 Broadhead WE, Kaplan BH, James SA, et al. The epidemiologic evidence for a relationship between socia support and health. $A m \mathcal{F}$ Epidemiol 1983; 117: 521-37. 2 Berkman LF. Social networks, support, and health: taking

3 Berkman LF, Syme SL. Social networks, host resistance, and mortality. A nine-year follow-up study of Alamed County residents. Am ₹ Epidemiol 1979; 109: 186-204.

4 House JS, Robbins C, Metzner HL. The association of social relationships and activities with mortality: prospective evidence from the Tecumseh community health study. $A m$ f Epidemiol 1982; 116: 123-40.

5 Schoenbach VJ, Kaplan BH, Fredman L, Kleinbaum DG. Social ties and mortality in Evans County, Georgia. $\mathrm{Am} \mathcal{F}$ Epidemiol 1986; 123: 577-91.

6 Seeman TE, Kaplan GA, Knusden L, Cohen R, Guralnik J. Seeman TE, Kaplan GA, Knusden L, Cohen R, Guralnik J.
Social network ties and mortality among the elderly in the Alameda County study. Am f Epidemiol 1987; 126: 714-23. Orth-Gomer K, Johnson JV. Social network interaction and
mortality. A six year follow-up study of a random sample of mortality. A six year follow-up study of a random sample

the Swedish population. $f$ Chron Dis $1987 ; 40$ : 949-57.

8 Blazer DG. Social support and mortality in an elderly community population. Am f Epidemiol 1982; 115: 684-94.
9 Welin L, Tibblin G, Svärdsudd K, et al. Prospective study of social influences on mortality. The Study of Men Born in 1913 and 1923. Lancet 1985; i: $915-8$.

10 Kaplan GA, Salonen JT, Cohen RD, Brand RJ, Syme SL, Puska P. Social connections and mortality from all cause and from cardiovascular disease: Prospective evidence from eastern Finland. Am 7 Epidemiol 1988; 128: 370-80.

11 Hanson BS, Isacsson JT, Janzon L, Lindell S-E. Social network and social support influence mortality in elderly network and social support influence mortality in elderly men. The prospective population study of "men born in

12 Reed D, McGee D, Yano K, Feinleib M. Social networks and coronary heart disease among Japanese men in Hawaii. and coronary heart disease among Ja

13 Berkman LF. Social network analysis and coronary heart disease. Adv Cardiol 1982; 29: 37-49.

14 Myrhed $M$. Alcohol consumption in relation to factors associated with ischemic heart disease. A co-twin control study. Acta Med Scand 1974; suppl 567.

15 SAS User's Guide. Version 5 edition. Cary, NC: SAS Institute, 1985

16 Doll R, Hill AB. Mortality in relation to smoking: ten years' observations of British doctors. BMf 1964; i: 1399-410.

17 Tibblin G. A population study of 50-year-old men. An analysis of the non-participation group. Acta Med Scand 1965; 178: 453-9.

18 Tibblin G, Welin L, Larsson B, Ljungberg I-L, Svärdsudd $K$. The influence of repeated health examinations on mortality in a prospective cohort study, with a comment on the autopsy frequence. The study of men born in 1913 . the autopsy frequence. The study

19 Lawrence PS. Chronic illness and socioeconomic status. In: Jaco EG, ed. Patients, physicians and illness. New York:

20 Cassel J. The contribution of the social environment to host resistance. Am f Epidemiol 1976; 104: 107-23.

21 House JS, Landis KR, Umberson D. Social relationships and health. Science 1988; 241: 540-5.

22 Jenkins $C D$. Social environment and cancer mortality in men. $N$ Engl f Med 1983; 308: 325-98. 